\title{
Çok Değişkenli Uyarlanabilir Regresyon Eğrileri (ÇDURE) ile Günlük Akarsu Akımlarının Tahmini-Haldizen Deresi Örneği
}

\author{
Estimation of Daily Streamflow Using Multivariate Adaptive Regression Splines (MARS)-A \\ Case Study of Haldizen Stream
}

\author{
Sinan NACAR ${ }^{* 1, a}$, Murat KANKAL ${ }^{1, b}$, M. Ali HINIS ${ }^{2, c}$ \\ ${ }^{1}$ Karadeniz Teknik Üniversitesi, Mühendislik Fakültesi, Inşaat Mühendisliği Bölümü, 61080, Trabzon \\ ${ }^{2}$ Aksaray Üniversitesi, Mühendislik Fakültesi, İnşaat Mühendisliği Bölümü, 68100, Aksaray
}

• Geliş tarihi / Received: 09.05.2017 • Düzeltilerek geliş tarihi / Received in revised form: 04.10.2017 • Kabul tarihi / Accepted: 06.10.2017

\begin{abstract}
$\ddot{O} z$
Su yapılarının tasarımında ve işletmesinde günlük akarsu akım değerleri büyük öneme sahiptir. İleriye yönelik kısa süreli akım tahmini yapabilen bir metodun geliştirilmesi, işletmede bulunan su yapılarının kontrolünün sağlanması, hidroelektrik üretimi, çevre koruması ve taşkın kontrolünde üreticiye, kullanıcıya ve bölge halkına uygun bir yönetim imkânı sağlayabilmektedir. Bu çalışmada, Haldizen Deresi akım değerleri Çok Değiş̧kenli Uyarlanabilir Regresyon Eğrileri (ÇDURE) kullanılarak tahmin edilmiş ve sonuçlar klasik regresyon analizi (KRA) ile karşılaş̧ırılmıştır. Bu amaç doğrultusunda Doğu Karadeniz Havzası'nda yer alan Haldizen Deresi Şerah Akım Gözlem İstasyonunun 19982009 yılları arasında günlük olarak ölçülmüş olan akım verileri kullanılmıştır. Yapılan bu çalışma ile ÇDURE yönteminin tahmin değerlerinin KRA'ya göre daha iyi sonuçlar verdiği ve yöntemin akım değerleri tahmininde kullanılabilir olduğu sonucuna ulaşılmıştır. Bu çalışmanın akarsu üzerindeki enerji planlamasında ve ayrıca bölgede yapılması planlanan su koruma yapılarının tasarımında da faydalı olacağı düşünülmektedir.
\end{abstract}

Anahtar kelimeler: ÇDURE, Günlük Akım Değerleri Tahmini, Haldizen Deresi

\begin{abstract}
The daily streamflow values have a great influence on the design and operation of water structures. Development of a method capable of predicting future short-time current flow providing control of water structures in operation, hydroelectricity generation, environmental protection and flood control can provide appropriate management for producers, users and the people of the region. In this study, the Haldizen Stream streamflow values were estimated using Multivariable Adaptive Regression Splines (MARS) and compared with the result of Classical Regression Analysis (CRA). For this purpose, daily flow data measured between 1998 and 2009 of the Haldizen Stream Şerah Stream Observation Station located in the Eastern Black Sea Basin were used. With this study, it is concluded that the result of MARS method give a better than those of KRA method and can be used in estimating flow values. This study is thought to be useful in energy planning on the river and also in the design of water conservation plans planned to be made in the region.
\end{abstract}

Keywords: MARS, Daily Flow Estimation, Haldizen Stream

\footnotetext{
*a Sinan NACAR; sinannacar@ hotmail.com; Tel: (0554) 232 16 93; orcid.org/0000-0003-2497-5032

${ }^{b}$ orcid.org/0000-0003-0897-4742 $\quad{ }^{\mathrm{c}}$ orcid.org/0000-0002-1870-3535
} 


\section{Giriş}

Gelecekteki belli bir tarihte görülecek akımın (debi, seviye, akış hacmi) tahmini, taşkın uyarılarının yapılması, taşkın kontrolü maksatlı haznelerin ișletilmesi, akarsuyun su potansiyelinin belirlenmesi, kurak dönemlerde hidroelektrik üretiminin, şehir suyu ve sulama suyunun dağıtımı ve akarsularda ulaşımın planlanması açısından önem taşımaktadır (Alp ve Ciğızoğlu, 2010). Ayrıca günümüzde enerji ihtiyacının her geçen gün arttığı bir gerçektir. Fosil kaynaklardan elde edilen enerjinin oluşan talebi karşılamakta zorlandığı ve çevreye verilen zarar düşünülecek olduğunda, akarsu üzerinde inşa edilen ve enerji üretiminde büyük rolü olan su yapılarının uygun ve maksimum enerji elde edilecek yerlerde inşa edilmelerinin önemi de açıkça ortaya çıkmaktadır (Nacar, 2014). Tüm bu tespitler ileriye yönelik akım değerlerinin önceden bilinmesinin önemini açıkça ortaya koymaktadır. Bu durum göz önüne alındığında, hidrolik yapıların tasarım ve işletilmesinde, debi tahminlerinde ve havzalarda yerleşke kurmaktan taşkın tahliyesine kadar uzanan ilgi alanlarında tahmin modelleri kullanmak zorunlu hale gelmiştir (Yurtoglu, 2005). Bu çalışmanın amacı; çok değişkenli uyarlanabilir regresyon eğrileri (ÇDURE) ve klasik regresyon analizi (KRA) yöntemleri ile, geçmiş yıllara ait günlük akım değerleri kullanılarak ileriye yönelik akım değeri tahmininde bulunmaktır. Böylelikle yukarıda bahsedilen hususlarda yöneticilere ve işletmecilere ön bilgi sağlanmış olacaktır.

Literatürde debi değerlerinin önceden belirlenebilmesine yönelik ülkemizde bulunan pek çok akarsu üzerinde çalışmalar yapılmıştır. Bunlardan bazılarına kısaca yer verilmiştir. Turan (2007), çalışmasında akarsuların akım tahmini için Yapay Sinir Ağları (YSA) kullanmıştır. Bu çalışmada geçmiş akımlardan ve memba akım ölçüm değerlerinden nehir akımlarının tahminini amaçlamıştır. Okkan ve Mollamahmutoğlu (2010), çalışmalarında güvenilir akım tahminlerinin ve akım modellemelerinin yapılmasının su kaynakları planlaması ve tasarımındaki önemini vurgulamış ve Çoruh Nehri'ne ait günlük akım değerleri ile YSA kullanarak bir model geliştirmeye çalışmışlardır. Can (2012), YSA yöntemini kullanarak çeşitli alternatif durumlar için su yapılarının işlevsel, emniyetli ve ekonomik planlanması için gereken belirli bir zaman sürecine ait akım değerlerini tahmin etmeye çalışmışlardır.

İleriye yönelik akım değerlerinin tahmini çalışmaları sadece ülkemiz akarsularında değil, aynı zamanda dünyanın farklı bölgelerinde de birçok akarsu üzerinde araştırmacılar tarafindan incelenen bir konu olmuştur. Dawson ve Wilby (2001), İngiltere' de bulunan Thames ve Mole nehirlerinin akım tahminini yapmak amacıyla YSA metodunu kullanmışlardır. Sattari vd. (2012), YSA metodunu farklı model yapılariyla kullanarak, yağış akış ilişkisini iki aşamalı olarak ileriye yönelik tahmin etmeye çalışmışlardır. Latt ve Wittenberg (2014), YSA ve çoklu lineer regresyon yöntemleri ile Chindwin nehrine ait 1990-2011 yıllarının taşkın dönemlerine ait verileri kullanarak ileriye yönelik tahminde bulunmuşlardır. Sharda vd. (2008), çalışmalarında üç Orta-Himalaya mikro havzasında akışı tahmin etmek için ÇDURE tekniğini kullanmışlardır. Yine bir başka çalışmada Adamowski vd. (2012) Himalayalar'daki debi tahmini için yeterli verinin bulunmadığı Sainji dağlık havzasında akış tahmin uygulamaları için, ÇDURE, dalgacık dönüşümü yapay sinir ağı, YSA yöntemlerini kullanmış ve sonuçlarını kıyaslamışlardır. Bu çalışmaların yanı sıra birçok araştırmacı akarsu akım değerlerinin önceden belirlenmesinin önemini vurgulamış, farklı veri grupları ve yöntemler kullanarak bir çok çalışma gerçekleştirmiştir (Golob vd., 1998; Dibike ve Solomatine, 2001; Komornik ve Komornikova, 2006; Wang ve Chau, 2009; Okkan ve Serbes, 2012).

Literatür ile ilgili yapılan çalışmadan görüldüğü üzere, akım değerlerinin tahmini ile ilgili yapılan çalışmaların çoğunluğunda, başta YSA olmak üzere yapay zekâ tekniklerinden faydalanılmıştır. $\mathrm{Bu}$ çalışmada ise farklı bir yöntem olan ÇDURE'nin akım değerleri tahminindeki başarısının değerlendirilmesi amaçlanmıştır.

Bağımlı ve bağımsız değişkenler arasındaki fonksiyonel ilişkiye dair varsayımlarda bulunmayan ve parametrik olmayan bir regresyon yöntemi olan ÇDURE farklı mühendislik problemlerinin çözümünde başarıyla kullanılmıştır (Attoh-Okine vd., 2003; Jin vd., 2001; Litinetski ve Abramzon, 1998). Bunun yanında ÇDURE yöntemi akım değerlerinin tahmini çalışmalarında ülkemiz havzalarından birinde ilk kez kullanılacaktır. ÇDURE yöntemi ile elde edilen tahmin değerlerinin doğruluğu KRA yöntemi sonuçları ile kıyaslama yapılarak değerlendirilmiştir.

\section{Yöntem}

\section{1. Çok Değişkenli Uyarlanabilir Regresyon Ĕgrileri (ÇDURE)}

ÇDURE 1991 yılında Jerome Friedman tarafindan geliştirilmiştir (Özfalcı, 2008). ÇDURE bağımlı 
ve bağımsız değişkenler arasındaki fonksiyonel ilişkiye dair varsayımlarda bulunmayan ve parametrik olmayan bir regresyon yöntemidir. Bunun yerine regresyon verisinden kendisinin çıkardığı temel fonksiyonlara dayanarak kendisi bir ilişki oluşturmaktadır. Bağımsız değişkenlerin farklı aralıklarına karşılık gelen temel fonksiyonları kullanarak esnek bir regresyon modeli kurar (Toprak, 2011).

Genel ÇDURE modeli (1) nolu eşitlikteki gibi tanımlanabilir (Özfalcı, 2008).

$$
Y=\beta_{0}+\sum_{k=1}^{K} a_{k} \beta_{k}\left(X_{t}\right)+\varepsilon_{i}
$$

\section{Burada;}

$\mathrm{k}$ : düğüm sayısını,

$\mathrm{K}$ : temel fonksiyon sayısinı,

$\mathrm{X}$ : bağımsız değişkeni,

$\mathrm{a}_{\mathrm{k}}$ : $\mathrm{k}$. Temel fonksiyonun kat sayısı,

$\beta_{0}$ : modeldeki sabit terim,

$\beta_{k}\left(x_{t}\right)$ : t. Bağımsız değişken için k. Temel fonksiyon

Temel fonksiyon ise aşağıdaki (2) gibi tanımlanır.

$$
B_{m}(x)=\prod_{t=1}^{L_{m}}\left[S_{1, m}\left(x_{v(1, m)}-k_{1, m}\right)\right]
$$

Burada;

$\mathrm{L}_{\mathrm{m}}$ : etkileşim derecesini

$\mathrm{S}_{1}, \mathrm{~m}: \in[ \pm 1]$

$\mathrm{k}_{1}, \mathrm{~m}$ : düğüm değerini

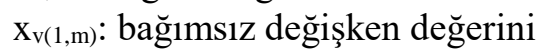

$\varepsilon_{\mathrm{i}}$ : hata terimini göstermektedir.

ÇDURE yönteminde istenen model elde edilene kadar tekrarlanan iki adımlı bir süreç vardır. Bu adımların ilkinde mümkün olan tüm temel fonksiyonlar oluşturulur. Çok büyük bir model bulununcaya kadar yani modelin karmaşıklığı maksimum seviyeye ulaşıncaya kadar eklenen temel fonksiyonlarla model geliştirilir. İkinci adımda oluşturulan maksimum model budanarak yani önemli bağımsı değişkenler ve bu değişkenlerin karşıllklı etkileşimleri belirlenerek, hata kareler toplamı minimum olan en uygun model oluşturulur. Budama algoritması en yaygın olarak genelleştirilmiş çapraz geçerlilik (GCV) tekniği ile yapılır. GCV hem hata terimini hem de model karmaşasını hesaba katar (Ünal, 2009; Uzlu, 2016).

\subsection{Klasik Regresyon Analizi (KRA)}

Mühendislik problemlerinin birçoğunda iki ya da daha çok sayıda rastgele değişkenin aynı gözlem sırasında aldıkları değerlerin istatistik bakımdan birbirinden bağımsız olmadığını ve dolayısıyla değişkenler arasında bir ilişkinin olduğu görülür. Bahsi geçen bu ilişkiler fonksiyonel değildir. Değişkenlerden biri bir değer aldığında, diğer değişken buna karşılık her zaman aynı değeri almaz. Değişkenler arasındaki fonksiyonel olmayan bu bağıntının ortaya çıkarılması büyük önem taşır. Bu bağıntıyı gösteren matematiksel ifadeye regresyon denklemi denir. (Bayazıt ve Yeğen, 2005). Bir rastgele değişkenin değerini bir veya daha fazla sayıda rastgele değişkenlerin değerlerine bağlı olarak en iyi şekilde tahmin etmeye yarayan regresyon denkleminin belirlenmesine de regresyon analizi denir (Bayazıt, 1981). Regresyon analizinin amac1, göz önüne alınan değişkenler arasında anlamlı bir ilişki bulunup bulunmadığını belirlemek, böyle bir ilişki varsa bu ilişkiyi ifade eden regresyon denklemini elde etmek ve bu denklemi kullanarak yapılacak tahminlerin güven aralıklarını hesaplamaktır (Şentürk, 2008).

KRA'da kullanılacak olan regresyon fonksiyonlarını belirleyebilmek için bir ön çalışma yapılmıştır. Bu çalışma sonucunda en iyi sonuçların elde edildiği ve sıklıkla kullanılan çoklu lineer, hiperbolik ve çoklu eksponansiyel fonksiyonları seçilmiştir (Uzlu vd., 2014; Bayram vd., 2012; Bayram vd., 2015; Ghiaei vd., 2016). KRA için kurulan denklemler aşağıda verilmiştir.

$$
y_{\text {lineer }}=w_{0}+w_{1} x_{1}+w_{2} x_{2}+w_{3} x_{3}+\ldots+w_{n} x_{n}
$$

$$
\begin{aligned}
& y_{\text {hiperbolik }}=w_{0} x_{1}^{w_{1}} x_{2}^{w_{2}} x_{3}^{w_{3}} x_{4}^{w_{4}} \ldots x_{n}^{b_{n}} \\
& y_{\text {exp onansiyel }}=w_{0}+\exp \left(w_{1}+w_{2} x_{1}+w_{3} x_{2}+\right. \\
& w_{4} x_{3}+w_{5} x_{4}+\ldots+w_{n+1} x_{n}
\end{aligned}
$$

\section{3. Çalışma Alanı ve Kullanılan Veriler}

Doğu Karadeniz Havzası; batıda Ordu il sınırı, doğuda Gürcistan sınırı, güneyde ise Doğu Karadeniz dağ silsilesi ve kuzeyde Karadeniz ile sınırlanan Türkiye'nin kuzeydoğu bölgesini oluşturur. Doğu Karadeniz Havzası, Türkiye' deki 26 akarsu havzasından birisidir. Havza; Melet Çayı, Harşit Çayı, Kara dere, Solaklı Deresi, 
Furtına deresi gibi birbirine paralel olarak uzanan akarsuların alt havzalarından oluşur (Nacar, 2014). Türkiye'nin yıllık ortalama yağış miktarı $643 \mathrm{~mm}$ iken Doğu Karadeniz Havzasi her y1 ortalama olarak yaklaşık $1200 \mathrm{~mm}$ yağış almaktadır (Uzlu, 2011).

Çalışma bölgesi olarak Doğu Karadeniz Havzası'nda bulunan Haldizen Deresi seçilmiştir. Doğu Karadeniz Havzası Türkiye'nin en fazla yağış alan havzası olması ve dağlık bir yapıya sahip olması sebebiyle önemli miktarda hidroelektrik potansiyeline sahiptir. Bölgede EİE ve DSİ tarafindan yapılan, inşası devam eden ve yapılmas1 planlanan 292 Hidroelektrik Santral (HES) projesi bulunmaktadır. Bölgede bulunan HES'lerden ve barajlardan üretilen elektrik 1216,97 GWs/yıl olarak Türkiye'nin 129500
GWs/y1l olan y1llı hidroelektrik üretiminin \%0,94'lük kısmını oluşturmaktadır (Uzlu, 2011). Çalışmada verileri kullanılan Haldizen Deresi, Trabzon il sınırları içerisindeki Solaklı havzasının yan kollarından biridir. Şekil 3.1'de Solaklı Deresinin anakol ve yan kolları verilmiştir. Solaklı vadisinin sahip olduğu engebeli arazi akarsuların düşüm yüksekliklerini arttırmış ve bu sayede havzanın hidroelektrik potansiyelini de önemli ölçüde etkilemiştir (Algancı vd., 2010).

Haldizen deresi üzerinde bulunan DSI'ye ait Şerah Akım Gözlem İstasyonu'nun (AGI) 19982009 yılları arasındaki günlük akım değerleri ileriye yönelik tahmin modellerinde kullanılmıştır. Haldizen Deresi'nin akım değerlerinin ölçüldüğü Şerah AGI'ye ait bilgiler Tablo 3.1'de verilmiştir.

Tablo 3.1. Haldizen Şerah AGİ bilgileri.

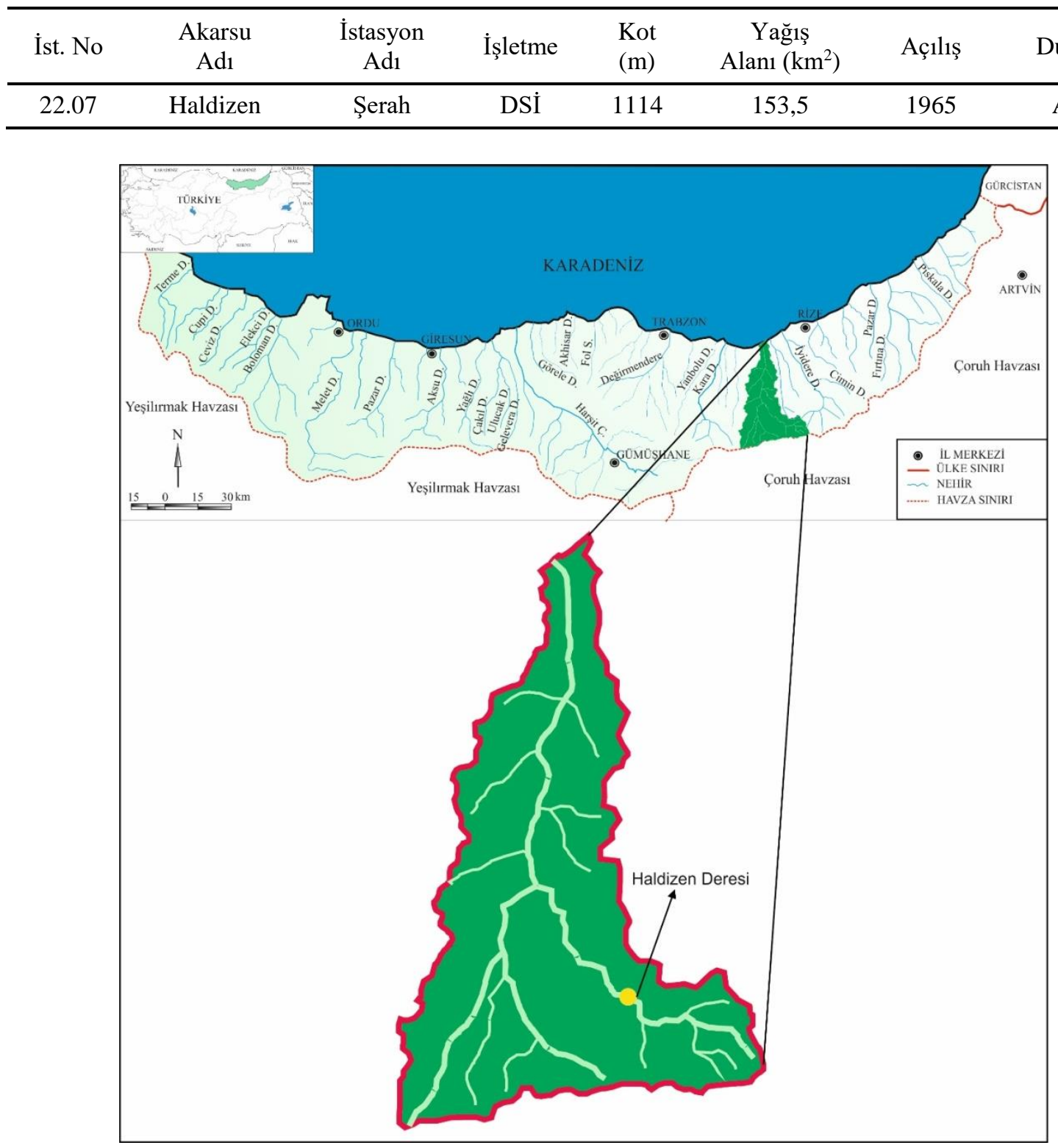

Şekil 3.1. Solaklı Deresi anakol ve yankolları. 


\section{Yapılan Çalışmalar}

Çalı̧̧mada Haldizen Deresi üzerinde bulunan Şerah AGI'ye ait 4291 adet günlük ortalama akım verisi kullanılarak ileriye yönelik akım tahmininde bulunulmuştur. Kullanılan 1998-2009 y1llar1 aras1 4291 adet verinin ilk 3351'i (\%78) eğitim, sonraki 940'i (\%22) doğrulama için kullanılmıştır. Verilerin bu oranlarda bölünmesinin sebebi doğrulama veri takımı içerisinde maksimum akım değerlerinin bulunmasının istenmesidir. Böylelikle kurulan modelin maksimum akım değerlerini tahmin etmedeki doğruluğu da değerlendirilmiş olacağı düşünülmüsşür. Kullanılan eğitim ve doğrulama veri takımına ait zaman serisi Şekil 3.2'de verilmiştir.
Çalışmada kullanılan veri takımına ait istatistiksel analiz Tablo 3.2'de sunulmuştur.

Tablo 3.2. Eğitim ve doğrulama veri takımına ait istatistiksel analiz

\begin{tabular}{lcc}
\hline İstatistik Değerler & Ĕ̈itim & Doğrulama \\
\hline Ortalama $\left(\mathrm{m}^{3} / \mathrm{sn}\right)$ & 3,81 & 4,62 \\
Standart Sapma $\left(\mathrm{m}^{3} / \mathrm{sn}\right)$ & 4,10 & 5,21 \\
Basılılk & 3,85 & 6,93 \\
Çarpıklık & 1,89 & 2,39 \\
En Büyük $\left(\mathrm{m}^{3} / \mathrm{sn}\right)$ & 35,10 & 33,00 \\
En Küçük $\left(\mathrm{m}^{3} / \mathrm{sn}\right)$ & 0,42 & 0,78 \\
Veri Adedi & 3351 & 940 \\
Veri Yüzdesi $(\%)$ & 78 & 22 \\
\hline
\end{tabular}

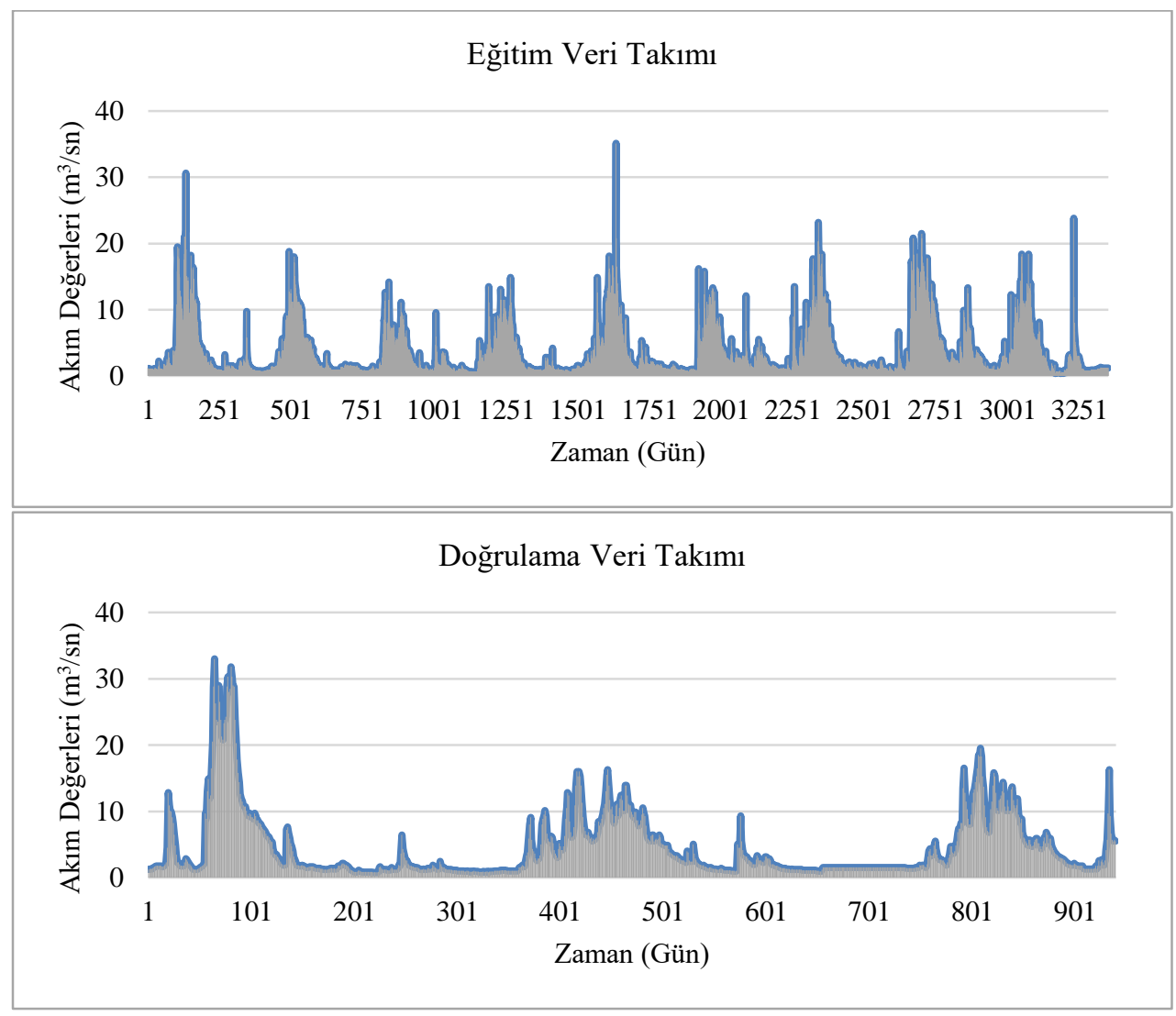

Şekil 3.2. Haldizen Deresi Şerah AGİ 1998-2009 günlük ortalama akım değerlerine ait eğitim ve doğrulama veri gruplarının zaman serileri.

Tablodan görüleceği üzere standart sapma ortalama değerlerin üzerindedir. Ayrıca çarpıklık katsayısının pozitif olması dağılımın sağa çarpık olduğunu göstermektedir. $\mathrm{Bu}$ durum verilerin simetrik olarak dağılmadığını ve tahmini zor olan bir veri grubu seçildiğini göstermektedir.

Çalışmada günlük akım değerleri birer gün ötelenerek değişkenler oluşturulmuştur. $\mathrm{Bu}$ yöntemle üç farklı model kurulmuş ve her model için bir gün sonrası akım değerleri tahmini yapılmıştır. Modellerde değişken sayısı olarak en fazla üç değişken belirlenmiştir. Bunun sebebi değişken sayısının artmasına bağlı olarak korelasyonun azalmasıdır (Tablo 3.3). Bu çalışmada korelasyon değerinin $\% 90$ altında bulunan değişkenler dikkate alınmamıştır. 
Tablo 3.3. Değişkenler arasındaki korelasyon değişimi.

\begin{tabular}{llllllll}
\hline Korelasyon & $\mathrm{Q}_{\mathrm{t}-1}$ & $\mathrm{Q}_{\mathrm{t}-2}$ & $\mathrm{Q}_{\mathrm{t}-3}$ & $\mathrm{Q}_{\mathrm{t}-4}$ & $\mathrm{Q}_{\mathrm{t}-5}$ & $\mathrm{Q}_{\mathrm{t}-6}$ & $\mathrm{Q}_{\mathrm{t}-7}$ \\
\hline $\mathrm{Q}_{(\mathrm{t})}$ & 0,96 & 0,93 & 0,90 & 0,87 & 0,85 & 0,83 & 0,81 \\
\hline
\end{tabular}

Çalışmada kullanılan modeller aşağıdaki gibidir;

Model 1: $Q_{t}=f\left(Q_{(t-1)}\right)$

Model 2: $\mathrm{Q}_{\mathrm{t}}=\mathrm{f}\left(\mathrm{Q}_{(\mathrm{t}-1)}, \mathrm{Q}_{(\mathrm{t}-2)}\right)$

Model 3: $\mathrm{Q}_{\mathrm{t}}=\mathrm{f}\left(\mathrm{Q}_{(\mathrm{t}-1)}, \mathrm{Q}_{(\mathrm{t}-2)}, \mathrm{Q}_{(\mathrm{t}-3)}\right)$

ÇDURE ve KRA için kurulan modellerden de anlaşılacağı üzere bir gün sonrası akım değerleri çeşitli girdi senaryolarına göre tahmin edilmeye çalışılmıştır. Elde edilen sonuçlar aşağıda denklemleri verilen, iki değişken arasında doğrusal bir ilişki olup olmadığını bulabilmemizi sağlayan, korelasyon katsayısı $\left(\mathrm{R}^{2}\right)$, ortalama karesel hatanın karekökü (OKHK), ortalama mutlak hata $(\mathrm{OMH})$ ve rölatif hata $(\mathrm{RH})$ kriterlerine göre değerlendirilmiş ve en doğru sonucu veren model belirlenmeye çalışılmıştır. Bu kriterlerde $\mathrm{G}$ ölçüm değerleri $\mathrm{T}$ ise tahmin edilen değerleri ve $\mathrm{N}$ veri adedini temsil etmektedir.

$$
\begin{aligned}
& R=\frac{\sum G T-\frac{\sum G \sum T}{N}}{\sqrt{\left(\sum G^{2}-\frac{\left(\sum G\right)^{2}}{N}\right)\left(\sum T^{2}-\frac{\left(\sum T\right)^{2}}{N}\right)}} \\
& O K H K=\sqrt{\frac{1}{N} \sum_{i=1}^{N}(G-T)^{2}} \\
& O M H=\frac{\sum|G-T|}{N} \\
& R H=\frac{(G-T)}{G} \frac{100}{N}
\end{aligned}
$$

Çalışmada kullanılan faklı tipteki eşitliklere ait doğrulama takımı için elde edilen OKHK ve $R^{2}$ değerleri Tablo 3.4'de sunulmuştur. Değerler çalışmada kullanılan 3 farklı model için ayrı ayrı hesaplanmıştır ve her bir eşitlik tipi için elde edilen en iyi model tabloda koyu olarak gösterilmiştir. Tablo incelendiğinde, KRA için kullanılan denklemlerde tek girdi değişkeninin $\mathbf{Q}_{(t-}$ 1) kullanıldığ 1 Model-1'in daha iyi sonuçlar verdiği görülmektedir. ÇDURE yönteminde ise tüm bağımsız değişkenlerin kullanıldığ 1 Model 3 'ün diğer modellere göre daha düşük hata değeri verdiği görülmektedir. Genel bir değerlendirme yapıldığında, OKHK ve $R^{2}$ değerleri tüm eşitlik ve model tipleri için birbirine oldukça yakın olduğu görülmektedir. Bunun yanında en iyi modelin 1.11'lik OKHK ve 0.956 'lık $R^{2}$ değeri ile ÇDURE yönteminin kullanıldığı Model-3 olduğu ortaya çıkmıştır. En düşük $\mathrm{OMH}$ ve $\mathrm{RH}$ değerleri de ÇDURE yöntemi ile elde edilmiştir. KRA'da en iyi modeller için elde edilen eşitlikler aşağıda verilmiştir. Eşitlik_10 KRA-Lineer, Eşitlik_11 KRA-Hiperbolik, Eşitlik_12 ise KRAEkponansiyel yöntemlerine ait en az hata veren denklemlerdir.

$Q_{(t)}=0,16108+0,957757 Q_{(t-1)}$

$Q_{(t)}=1,1289 Q_{(t-1)}^{0,93834684}$

$Q_{(t)}=-302,1458452+\exp \left(5,711661857+0,00308745 * Q_{(t-1)}\right)$

Tablo 3.4. Doğrulama takımı için modellerin değerlendirilmesi

\begin{tabular}{llllll}
\hline Eşitlik tipi & Model & OKHK & $R^{2}$ & RH & OMH \\
\hline KRA-Lineer & Model-1 & 1,1157 & 0,955 & 11,2587 & 0,5456 \\
& Model-2 & 1,1202 & 0,954 & 11,2663 & 0,5482 \\
\multirow{3}{*}{ KRA-Hiperbolik } & Model-3 & 1,1256 & 0,954 & 11,1874 & 0,5536 \\
& Model-1 & 1,1391 & 0,954 & 13,0536 & 0,5821 \\
& Model-2 & 1,1519 & 0,953 & 12,6280 & 0,5851 \\
KRA-Eksponansiyel & Model-3 & 1,1549 & 0,952 & 12,4741 & 0,5871 \\
& Model-1 & 1,1189 & 0,954 & 12,5010 & 0,5621 \\
& Model-2 & 1,1284 & 0,953 & 12,0958 & 0,5622 \\
ÇDURE & Model-3 & 1,1315 & 0,953 & 11,8682 & 0,5658 \\
& Model-1 & 1,1494 & 0,953 & 9,6947 & 0,5500 \\
& Model-2 & 1,1208 & 0,954 & 10,2669 & 0,5376 \\
& Model-3 & $\mathbf{1 , 1 0 8 8}$ & $\mathbf{0 , 9 5 6}$ & $\mathbf{8 , 9 9 7 0}$ & $\mathbf{0 , 5 1 0 1}$ \\
\hline
\end{tabular}


ÇDURE yöntemi daha önce belirtildiği gibi, bağımlı ve bağımsız değişkenler arasındaki fonksiyonel ilişkiye dair varsayımlarda bulunmayan ve parametrik olmayan bir regresyon yöntemidir. Bunun yerine regresyon verisinden kendisinin çıkardığı temel fonksiyonlara dayanarak kendisi bir ilişki oluşturmaktadır. ÇDURE yöntemindeki en iyi model olan Model-3 için elde edilen temel fonksiyonlar Tablo 3.5 'de verilmiştir. Yöntemde analiz yapılırken en büyük temel fonksiyon adedi 30 olarak belirlenmiştir. Tablodan da görüldügü gibi oluşturulan tüm temel fonksiyonlar modelde kullanılmamaktadır.

Tablo 3.5. Model-3 için ÇDURE yöntemindeki temel fonksiyonlar.

\begin{tabular}{ll}
\hline Temel Fonksiyon No & Temel Fonksiyonlar \\
\hline BF1 & $\max \left(0, \mathrm{Q}_{(\mathrm{t}-1)}-6.3\right)$ \\
BF2 & $\max \left(0,6.3-\mathrm{Q}_{(\mathrm{t}-1)}\right)$ \\
BF3 & $\max \left(0, \mathrm{Q}_{(\mathrm{t}-2)}-2.89\right) * \mathrm{BF} 2$ \\
BF7 & $\max \left(0, \mathrm{Q}_{(\mathrm{t}-1)}-1.93\right)$ \\
BF9 & $\max \left(0, \mathrm{Q}_{(\mathrm{t}-2)}-7.5\right) * \mathrm{BF} 7$ \\
BF10 & $\max \left(0,7.5-\mathrm{Q}_{(\mathrm{t}-2)}\right) * \mathrm{BF7}$ \\
BF12 & $\max \left(0,6.3-\mathrm{Q}_{(\mathrm{t}-2)}\right)$ \\
BF14 & $\max \left(0, \mathrm{Q}_{(\mathrm{t}-\mathrm{-})}-0.42\right) * \mathrm{BF} 7$ \\
BF21 & $\max \left(0, \mathrm{Q}_{(\mathrm{t}-2)}-1.93\right)$ \\
BF23 & $\max \left(0, \mathrm{Q}_{(\mathrm{t}-1)}-7.5\right) * \mathrm{BF} 21$ \\
BF25 & $\max \left(0, \mathrm{Q}_{(\mathrm{t}-1)}-2.8\right) * \mathrm{BF12}$ \\
BF27 & $\max \left(0, \mathrm{Q}_{(\mathrm{t}-2)}-1.77\right) * \mathrm{BF} 2$ \\
\hline
\end{tabular}

Bağımsız değişkenlerin farklı aralıklarına karşılık gelen temel fonksiyonları kullanarak esnek bir regresyon modeli Model-3 için kurulmuş ve Eşitlik_13'te verilmiştir. Bu eşitlik tüm analizler sonucunda en az hata değerini veren eşitlik olarak ortaya çıkmıştır.

$\mathrm{Q}_{(\mathrm{t})}=6,33514+0,578065 * \mathrm{BF} 1-1,46101 * \mathrm{BF} 2$ $+0,2246 * \mathrm{BF} 3+1,49744 * \mathrm{BF} 7+0,220018 *$ $\mathrm{BF} 9-0,176797 * \mathrm{BF} 10+0,46044 * \mathrm{BF} 12+$ $0,00629391 * \mathrm{BF} 14-1,34343 * \mathrm{BF} 21-0,22348 *$ $\mathrm{BF} 23-0,215597 * \mathrm{BF} 25+0,183032 * \mathrm{BF} 27$

Eşitlik.13 kullanılarak doğrulama takımı için elde edilen tahmin değerleri ile ölçüm değerleri Şekil 3.3'de zaman serisi olarak karşılaştırılmıştır. Şekil incelendiğinde, veri adedinin çok olması nedeniyle ölçüm ve tahmin değerleri arasındaki farkların tam olarak görünmesinde güçlükler yaşanmaktadır. Bu yüzden ayrı bir seri olarak hata değerleri de şekle eklenmiştir. Şekil incelendiğinde ölçüm ve tahmin değerleri arasında genel bir uyumun olduğu gözlenmektedir. Hata miktarlarına bakıldığında, en büyük hatanın 10 $\mathrm{m}^{3} / \mathrm{s}$ 'yi geçmediği ve genel olarak da $5 \mathrm{~m}^{3} / \mathrm{s}^{\prime}$ nin altında olduğu görülmektedir.

Verilerdeki hata miktarının debi değerlerinin hangi aralığında daha fazla ya da az olduğunu gözlemlemek için tahmin ve ölçüm değerleri arasında saçılım grafiğgi çizilmiş ve Şekil 3.4'de sunulmuştur. Şekil incelendiğinde, yöntemin küçük debi değerlerini tahmin etmede daha başarılı olduğu gözlenmektedir. Özellikle 25 $\mathrm{m}^{3} / \mathrm{s}$ 'nin üzerindeki debi değerleri tahmininde hata değerlerinin arttığı anlaşılmaktadır.

Tüm yöntem ve modeller arasında en iyi sonuç ÇDURE yöntemindeki Model-3'ten elde edilmiştir. Model-3'te toplamda üç bağımsız değişken kullanılmıştır. $\mathrm{Bu}$ bağımsız değişkenlerin bağımlı değişken üzerindeki göreceli etki oranları Tablo 3.6' da verilmiştir. Tablodan model üzerindeki en büyük etkinin $\mathrm{Q}_{(\mathrm{t}-}$ 1)'de olduğu ve bunu sirasiyla $\mathrm{Q}_{(\mathrm{t}-2)}$ ve $\mathrm{Q}_{(\mathrm{t}-3)}$ ' $\ddot{\text { ün }}$ takip ettiği görülmektedir. Özellikle $\mathrm{Q}_{(\mathrm{t}-3)}$ 'ün etkisinin oldukça düşük olduğu görülmektedir. $\mathrm{Bu}$ şekilde, daha önce elde edilen bağıml ve bağımsız değişkenler arasındaki korelasyon değerlerine uyumlu bir sonuç ortaya çıkmıştır.

Tablo 3.6. Her bir bağımsız değişkenin göreceli etki oranı

\begin{tabular}{ll}
\hline Değişken & Göreceli etki oran1 \% \\
\hline $\mathrm{Q}_{(\mathrm{t}-1)}$ & 100,00 \\
$\mathrm{Q}_{(\mathrm{t}-2)}$ & 25,76 \\
$\mathrm{Q}_{(\mathrm{t}-3)}$ & 5,46 \\
\hline
\end{tabular}

\section{Sonuçlar}

$\mathrm{Bu}$ çalışmada günlük akım verilerinin tahmini için ÇDURE yöntemi kullanılabilirliği araştırılmış ve yöntemin doğruluğu KRA ile kiyaslanarak değerlendirilmiştir. Çalışma bölgesi olarak önemli bir su potansiyeline sahip Doğu Karadeniz Havzası'nda bulunan Haldizen Deresi seçilmiştir. Haldizen Deresi üzerinde bulunan AGİ ile 1998 ile 2009 yılları için ölçülmüş olan günlük akım verilerinin \% 78'lik kısmı modellerin eğitimi için, geri kalan kısmı ise modelleri doğrulamak için kullanılmıştır. 


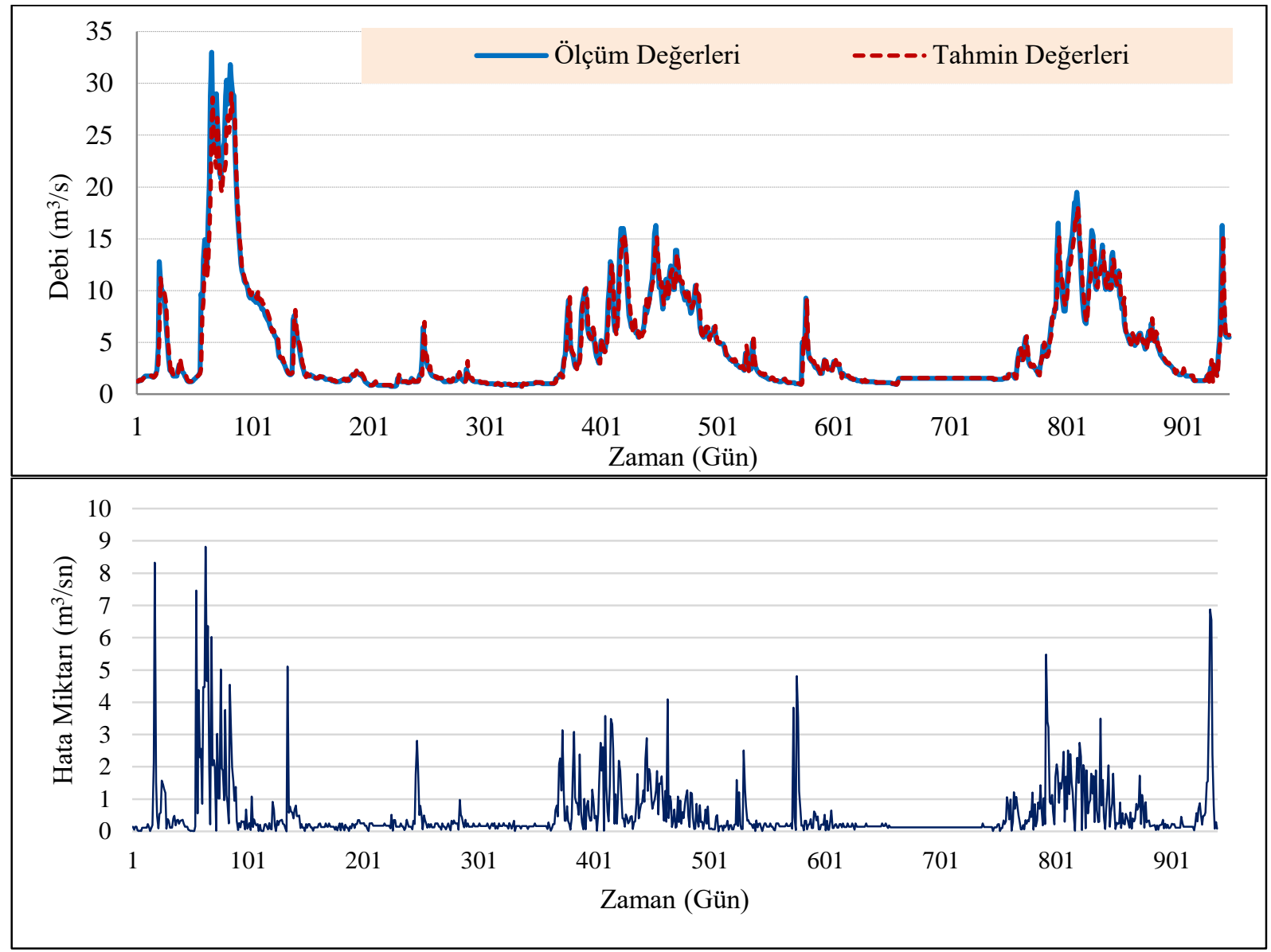

Şekil 3.3 En iyi ÇDURE modeli için doğrulama takımında ölçüm-tahmin değerlerinin karşılaştırılması ve hata miktarı

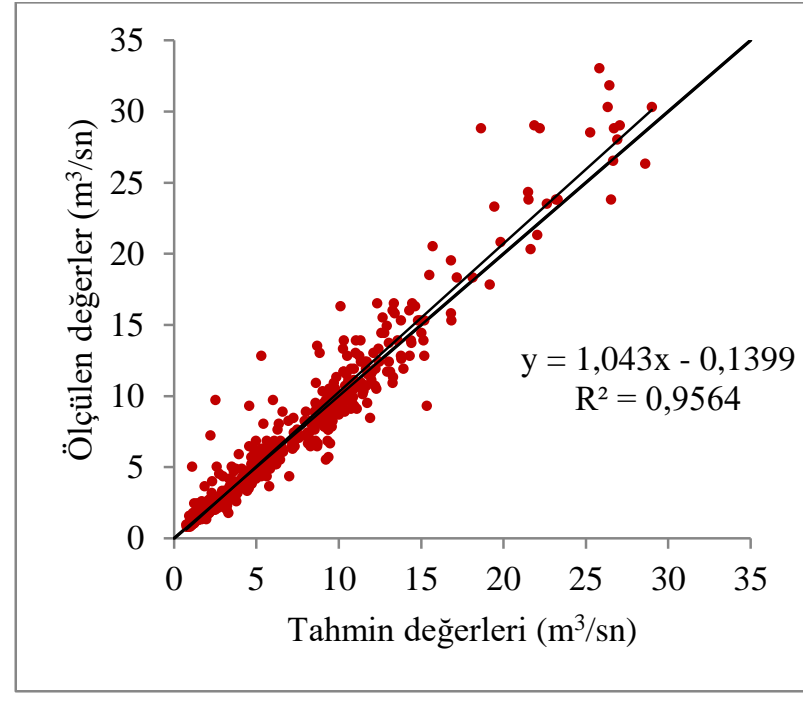

Şekil 3.4. En iyi ÇDURE modeli (Model-3) için ölçüm ve tahmin değerlerinin saçılım grafiği.

Model sonuçları değerlendirildiğinde bir gün sonras1 akım değerlerinin tahmininde en iyi sonuçların ÇDURE'den elde edildiği görülmüştür. İleriye yönelik akım tahmini için kurulan modellerden Model 3 ÇDURE'de, Model 1 ise KRA'da bütün fonksiyonlarda en düşük hata değerini vermiştir. ÇDURE yöntemi ile elde edilen göreceli etki oranlarına bakıldığında en büyük etkinin \%100 lük bir değer ile $\mathrm{Q}_{(\mathrm{t}-1)}$ 'e ait olduğu görülmüş̧ür. $\mathrm{Q}_{(\mathrm{t}-3)}$ için bu değer $\% 5$ seviyelerine düşmüştür. $\mathrm{Bu}$ durum bağımsız değişken sayısının arttırılmasının tahmin sonuçlarının doğruluğunu arttırmayacağını ortaya koymaktadir.

Model sonuçları değerlendirildiğinde yöntemlerin birbirlerine yakın sonuçlar verdiği ve hata değerleri arasındaki farkların büyük olmadığı görülmüştür. Kurak döneme ait akım değerlerinin tahmininde hata oranları oldukça düşük iken yă̆gşlı dönemlerdeki akım değerlerinin tahmininde hata değerlerinin nispeten arttığ1 görülmüştür. Çalışmadan elde edilen sonuçların kısa süreli akım tahmini gerektiren su yapılarının tasarımı, planlanması ve işletilmesinde kullanılabilir olduğu sonucuna varılmıştır. Ayrıca çalışma bölgesi olarak seçilen Doğu Karadeniz Havzası almış olduğu yüksek miktarda yağış ve sahip olduğu coğrafi yapı sebebiyle sürekli olarak taşkınlara maruz kalmaktadır. Meydana gelen 
taşkınlarda can ve mal kayıpları meydana gelmektedir. Bunun yanında bölgenin hidroelektrik potansiyeli oldukça yüksektir. Günlük akarsu akım değerlerinin önceden belirlenebilmesi kurulmuş olan ve kurulacak olan HES'lerin işletilmesi ve planlanması açısından oldukça önemlidir. Kısa süreli akım tahminlerinin yapılması hem HES'lerin planlanması, inşası ve işletmesinde hem de taşkın olaylarının önüne geçilmesi ve meydana gelen can ve mal kayıplarının en aza indirilmesi çalışmalarında yürütücülere yol gösterici olacağ1 düşünülmektedir.

\section{Kaynaklar}

Adamowski, J., Chan, H. F., Prasher, S. O., Sharda, V. N., 2012. Comparison of multivariate adaptive regression splines with coupled wavelet transform artificial neural networks for runoff forecasting in Himalayan micro-watersheds with limited data. Journal of Hydroinformatics, 14(3), 731-744.

Algancı, U., Coşkun, H. G., Eriş, E., Ağıralioğlu, N., Ciğızoğlu, K., Yılmaz, L., Toprak, Z. F., 2010. Akım ölçümleri olmayan akarsu havzalarında hidroelektrik potansiyelin belirlenmesine yönelik uzaktan algılama ve CBS ile hidrolojik modelleme, Jeoinformasyon ve Arazi Yönetimi Dergisi, 101-102.

Alp, M., ve Cığızoğlu, H. K., 2010. Farklı yapay sinir ağı metodları ile yağış-akış ilişkisinin modellenmesi. İTÜdergisi/d, 3(1).

Attoh-Okine, N. O., Mensah, S., Nawaiseh, M., 2003. A new technique for using multivariate adaptive regression splines (MARS) in pavement roughness prediction. In Proceedings of the Institution of Civil Engineers-Transport (Vol. 156, No. 1, pp. 51-55).

Bayram, A., Kankal, M., Önsoy, H. (2012). Estimation of suspended sediment concentration from turbidity measurements using artificial neural networks. Environmental monitoring and assessment, 184(7), 4355-4365.

Bayram, A., Uzlu, E., Kankal, M., Dede, T. (2015). Modeling stream dissolved oxygen concentration using teaching-learning based optimization algorithm.
Environmental Earth Sciences, 73(10), 6565-6576.

Bayazıt, M., 1981. Hidrolojide istatistik yöntemler, İTÜ Matbaası, Gümüşsuyu, İstanbul.

Bayazıt, M., Yeğen Oğuz, B., 2005. Mühendisler için istatiktik, Birsen Yayınevi, İstanbul.

Can, M., 2012. Yapay sinir ağları ile akım tahmini: Mahmudiye Göleti örneği, Yüksek Lisans Tezi, İstanbul Kültür Üniversitesi, Fen Bilimleri Enstitüsü, İstanbul.

Dawson C. W., Wilby R.L., 2001. Hydrological modelling using artificial neural networks, Progress in Physical Geography, 25, 1, 80108.

Dibike, Y.B., Solomatine, D.P., 2001. River flow forecasting using artificial neural networks, Physics Chemical Earth, 26, 1, 1-7.

Friedman, J. H., 1991. Multivariate adaptive regression splines. The annals of statistics, $1-67$.

Ghiaei, F., Kankal, M., Anilan, T., \& Yuksek, O. (2016). Regional intensity-durationfrequency analysis in the Eastern Black Sea Basin, Turkey, by using L-moments and regression analysis. Theoretical and Applied Climatology, 1-13.

Golob R., Stokelj T., Grgic D., 1998. Neural network- based inflow forecasting, Control Engineering Practice, 6, 593-600.

Jin, R., Chen, W., Simpson, T. W., 2001. Comparative studies of metamodelling techniques under multiple modelling criteria. Structural and multidisciplinary optimization, 23(1), 1-13.

Komornik, j., Komornikova, M., Mesiar, R., Szökeova, D., Szolgay, J., 2006. Comparison of forecasting performance of nonlinear models of hydrologicaltime series, Physics and Chemistry of The Earth $31,1127-1145$.

Latt, Z. Z., and Wittenberg, H., 2014. Improving flood forecasting in a developing country: a comparative study of stepwise multiple linear regression and artificial neural network. Water resources management, 28(8), 2109-2128. 
Litinetski, V. V., Abramzon, B. M., 1998. MARSA multistart adaptive random search method for global constrained optimization in engineering applications. Engineering optimization, 30(2), 125-154.

Nacar, S., 2014. Farklı Yapay Zeka Yöntemleriyle günlük akarsu akım değerlerinin tahminiHaldizen Deresi örneği, Yüksek Lisans Tezi, Aksaray Üniversitesi, Fen Bilimleri Enstitüsü, Aksaray

Okkan, U., Mollamahmutoğlu, A., 2010. Çoruh nehri günlük akımlarının yapay sinir ağlarıyla tahmin edilmesi, Süleyman Demirel Üniversitesi Fen Bilimleri Enstitüsü Dergisi, 14, 3, 251-261.

Okkan, U., Serbes, Z. A., 2012. Rainfall-runoff modeling using least squares support vector machines. Environmetrics, 23(6), 549-564.

Özfalcı, Y., 2008. Çok Değişkenli Uyarlanabilir Regresyon Kesitleri: Mars, Yüksek Lisans Tezi, Gazi Üniversitesi, Fen Bilimleri Enstitüsü, Ankara.

Sattari, M. T., Apaydin, H., \& Ozturk, F. (2012). Flow estimations for the Sohu Stream using artificial neural networks. Environmental Earth Sciences, 66(7), 2031-2045.

Sharda, V. N., Prasher, S. O., Patel, R. M., Ojasvi, P. R., Prakash, C., 2008. Performance of Multivariate Adaptive Regression Splines (MARS) in predicting runoff in midHimalayan micro-watersheds with limited data/Performances de régressions par splines multiples et adaptives (MARS) pour la prévision d'écoulement au sein de microbassins versants Himalayens d'altitudes intermédiaires avec peu de données. Hydrological sciences journal, 53(6), 1165 1175.

Şentürk, K., 2008. Akım Gözlem İstasyonu Olmayan Havzalarda su potansiyelinin belirlenmesi, Yüksek Lisans Tezi, İstanbul Teknik Üniversitesi, Fen Bilimleri Enstitüsü, İstanbul.
Toprak, S., 2011. Çok değişkenli uyarlamalı regresyon eğrileri ve konik programlama ile zaman serilerinin modellenmesi, Yüksek Lisans Tezi, Dicle Üniversitesi, Fen Bilimleri Enstitüsü, Diyarbakır.

Turan, M.E., 2007. Akarsu akımlarının tahmininde yapay zeka tekniklerinin kullanılması, Yüksek Lisans Tezi, Celal Bayar Üniversitesi, Fen Bilimleri Enstitüsü, Manisa

Uzlu, E., Kömürcü, M. İ., Kankal, M., Dede, T., Öztürk, H. T. (2014). Prediction of berm geometry using a set of laboratory tests combined with teaching-learning-based optimization and artificial bee colony algorithms. Applied Ocean Research, 48, 103-113.

Uzlu, E., 2016. Kıyıya dik katı madde hareketi sonucu oluşan yığılma profilinin fiziksel modelle incelenmesi, Doktora Tezi, Karadeniz Teknik Üniversitesi, Fen Bilimleri Enstitüsü, Trabzon.

Uzlu, E., Akpınar, A., Kömürcü, M.İ., 2011. Restructuring of Turkey's electricity market and the share of hydropower energy: The case of the Eastern Black Sea Basin, Renewable Energy 36, 676-688.

Ünal, B., 2009. Çok değişkenli uyarlamalı regresyon uzanımları, Yüksek Lisans Tezi, Hacettepe Üniversitesi, Fen Bilimleri Enstitüsü, İstanbul.

Wang, W., Chau, K., Cheng, C., Qiu, L., 2009. A comparison of performance of several artificial intelligence methods for forecasting monthly discharge time series, Journal of Hydrology, 374, 294-306.

Yurtoğlu, H., 2005. Yapay sinir ağları metodolojisi ile öngörü modellemesi: Bazı makroekonomik değişkenler için Türkiye Örneği, Uzmanlık Tezi, Ekonomik Modeller ve Stratejik Araştırmalar Genel Müdürlüğü, Ankara. 